\title{
Metodologia ativa na graduação: Relações de ensino- aprendizagem na abordagem do Design Thinking
}

Active methodology in the graduation: Teaching-learning relations in the approach of Design Thinking

ANGEOLETI, Larissa; Mestre; Univille

larissa.angeoleti@gmail.com

CANÔNICA, Rosangela, Mestre; Univille

canonicarosangela@gmail.com

SCHULENBURG, Haro, Mestre; Univille

harodesigner@gmail.com

PEZZINI, Marina, Mestre; Univille

marinapzn@gmail.com

SCHULENBURG, Roy, Mestre; Univille

royzera@gmail.com

\section{Resumo}

Este artigo refere-se ao relato de experiência no ensino superior, considerando os pressupostos do design thinking como parâmetro e componente de metodologia ativa de ensino-aprendizagem. Trata-se de experiências vivenciadas por acadêmicos de uma mesma turma do curso de Design (Interiores e Projeto de Produto). As relações práticas abordadas no processo de ensinoaprendizagem estão voltadas às reais necessidades das pessoas, considerando a melhoria da qualidade de vida de diferentes comunidades para o desafio projetual. Do primeiro ao quarto ano da graduação é possível delinear um importante comparativo entre o processo, técnicas e ferramentas ensinada no primeiro ano e os resultados obtidos com o uso dela no quarto ano, além da metodologia ativa de ensino-aprendizagem sendo explorada, que resultaram em soluções plausíveis para problemas reais percebidos na sociedade.

Palavras Chave: Design Thinking, metodologia ativa, ensino-aprendizagem e vivências sociais.

\begin{abstract}
This article refers to the report of experience in higher education, considering the assumptions of design thinking as a parameter and component of active teaching-learning methodology. These are experiences experienced by academics from the same class of Design course (Interiors and Product Project). The practical relationships addressed in the teaching-learning process are focused on the real needs of the people, considering the improvement of the quality of life of different communities for the project challenge. From the first to the fourth year of graduation, it is possible to delineate an important comparative between the process, techniques and tools taught in the first year and the results obtained with the use of it in the fourth year, in addition to the active teaching-learning methodology being explored, plausible solutions to perceived real problems in society.
\end{abstract}


Keywords: Design Thinking, active methodology, teaching-learning and social experiences.

\section{Introdução}

Este artigo apresenta experiências de ensino-aprendizagem fundamentadas no design thinking, realizadas com uma mesma turma de estudantes da graduação em Design da Univille em seus dois distintos períodos acadêmicos. No primeiro ano da graduação, em 2014, os acadêmicos tiveram o primeiro contanto com o design thinking, na disciplina de Metodologia de Projeto, cuja experiência prática de ensino "implicou em soluções plausíveis para problemas reais percebidos em espaços de uso coletivo" (CANÔNICA, ANGEOLETI, Et al. 2015. p.55). A ênfase desta segunda experiência, visto que a turma alcançou o quarto ano da graduação, refere-se ao ano de 2017, quando na disciplina de Design de Serviços, os acadêmicos projetam soluções plausíveis no contexto social utilizando como diretriz os pressupostos do design thinking aprendidos no início da formação em design. A temática do segundo desafio para os acadêmicos do quarto ano do curso de design da Univille envolveu o engajamento social em propostas voltadas à comunidade de maneira a refletir sobre diferentes contextos. Como fator impulsionador, têm-se a utilização da sala de aula de metodologias ativas de ensino-aprendizagem integrando ainda mais as premissas do ensino colaborativo ao qual o design thinking se propõe.

Em síntese, o objetivo geral da disciplina de Design de Serviços foi tornar palpável aos acadêmicos um projeto direcionado a criação de soluções a partir de uma visão empática, considerando as reais necessidades das pessoas. As propostas criadas impactam na melhoria de serviços prestados à comunidade Joinvilense.

A pertinência desse novo relato destaca alguns aspectos que contribuíram para oportunizar uma vivência do ensino-aprendizagem de maneira mais enriquecedora, como o uso de sala de aula projetada para metodologias ativas de ensino-aprendizagem, o aprimoramento técnico dos alunos e, do contexto de exploração de desafios no campo teórico de impactos sociais.

\section{Salas de metodologias ativas de ensino-aprendizagem}

De acordo com CAVALCANTI e FILATRO (2016) o mundo em transformação demanda novos olhares à educação, exigindo daqueles que a ela se dedicam, repensar tempos, abordagens e relações nos espaços educativos. No caso do ensino superior, essas mudanças são condições para uma reinvenção. Nesse sentido, a principal característica é mudança no papel dos professores, que ao invés de serem detentores do conhecimento, passam a mediar o processo de aprendizagem para que os estudantes tornem-se protagonistas e autores do conhecimento.

O modelo de ensino precisa ser capaz de atribuir e se adaptar aos diversos contextos, assim, as salas projetadas considerando metodologias ativas de aprendizagem, propiciam um ensino dinâmico e híbrido, utilizando de instrumentos virtuais para a comunicação com os estudantes e planejando uma maneira mais atrativa para a construção de conhecimento.

Com o propósito de fomentar um ambiente com maior estímulo colaborativo e tecnológico, no ano de 2016, a Univille, inaugurou duas salas de aulas, projetadas com a intenção de colocar o estudante no centro do processo de aprendizagem, tendo ele um papel ativo na construção do conhecimento. As salas de "metodologias ativas de aprendizagem" passaram a serem inseridas na rotina dos acadêmicos, trazendo novas ferramentas a favor do ensino. 
Figura 1 - Sala de metodologia ativa

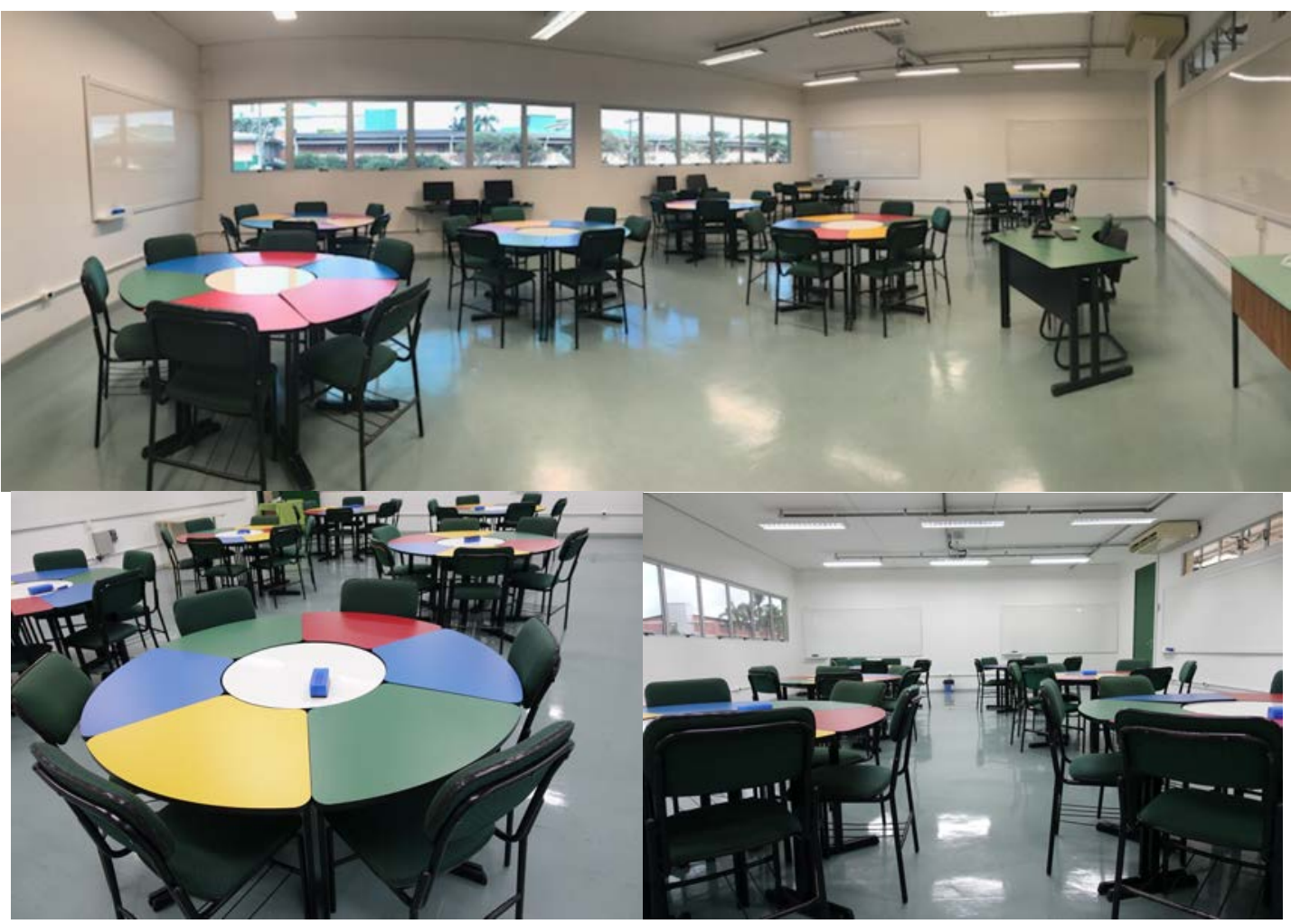

Fonte: o autor (2017)

Neste ambiente projetado para novas possibilidades de ensino, os acadêmicos do quarto ano do curso de Design, uniram-se em ações colaborativas mediada pela docente Larissa Angeoleti na disciplina de Design de Serviços. Esta segunda vivência, difere-se do primeiro ano, quando na disciplina de Metodologia do Projeto, a condução das aulas não pôde contar com a estrutura de sala de aula projetada na intenção de fomentar metodologias ativas. É importante considerar que, o uso da sala e de novas tecnologias no ensino favoreceu o interesse de participação dos alunos, ampliando o comprometimento e resultados obtidos em relação a vivência do primeiro ano de graduação dos acadêmicos.

Adotou-se a utilização do Design Thinking por, além de fazer parte do conteúdo programático previsto na ementa da disciplina Design de Serviços, conectar ferramentas colaborativas e empáticas, possibilitando a imersão em estudos de casos reais no contexto social. Neste sentido, as etapas conduziram os estudantes para alcançar soluções criativas para problemas que exigem colaboração, pensamento crítico e capacidade de inovação. Essa prática, permitiu a articulação da teoria aprendida com a prática profissional. O modelo adotado como estratégia de ensino-aprendizagem repercutiu, sobretudo, nos acadêmicos assumirem de forma dinâmica um papel ativo em sua aprendizagem.

CAVALCANTI e FILATRO (2016) relevam aspectos para o modelo pedagógico de cursos que 
adotam o design thinking como estratégia: (1) Apresentação dos conteúdos nas disciplinas curriculares aos alunos, pois quando os estudantes adquirem acesso à tópicos que precisam ser trabalhados na disciplina há o despertar do interesse; (2) Aprendizagem colaborativa e cooperativa, quando as atividades os novos saberes são construídos de forma coletiva e em rede; (3) Estímulo do aprender fazendo, aproximando o estudante do mundo profissional, pela articulação entre teoria vista no curso e a prática encontrada nos contextos sociais explorados.

Essa estratégia ativa de aprendizagem ainda possibilitou o desenvolvimento de uma a pesquisa com a ênfase no design centrado nos usuários, com os acadêmicos podendo vivenciar, desde o primeiro ano da graduação, situações reais para projetos focado nas necessidades das pessoas.

\section{Problematização e propostas de soluções à demandas sociais}

No contexto de projetar soluções a demandas sociais, um ambiente, produto ou serviço é entendido como o processo de apropriação em que o espaço passa a se adequar ao uso humanizado. A apropriação quer dizer "interação recíproca usuário/espaço", onde o usuário atua no sentido de moldar os lugares segundo suas necessidades e desejos. (MALARD, 2003). Nesse sentido, a demanda projetual explorada na sala de aula considerou aspectos sociais deficitários na cidade de Joinville após uma pauta de discussão compreendida como processo de imersão preliminar em sala de aula.

Como aborda Brown (2010), o design não constitui como uma simples resposta a problemas em uma formatação estética de formas, composições e linguagem. A ideação de alternativas inovadoras para desafios mais complexos projeta uma habilidade de desenvolver soluções realmente funcionais e criativas e que ainda possam propiciar um impacto social e econômico relevante. Portanto, é também importante salientar que, o design thinking busca o entendimento do usuário e do seu redor através da compreensão de suas "culturas, experiências, emoções, pensamentos e comportamentos de forma a reunir informações para inspirar o projeto" (VIANNA et al., 2012, p. 15). A metodologia apresenta etapas dinâmicas as quais podem ser reestruturadas de acordo com a necessidade de cada pesquisa, não necessitando de uma ordem linear. A flexibilidade permite uma maior compreensão de problemáticas a serem solucionadas e as fases consideradas pelos acadêmicos nos desafios partem da compreensão de uma problematização, classificam-se em: Imersão, análise, síntese, ideação e prototipação (figura 2).

Figura 2 - Etapas da metodologia Design thinking

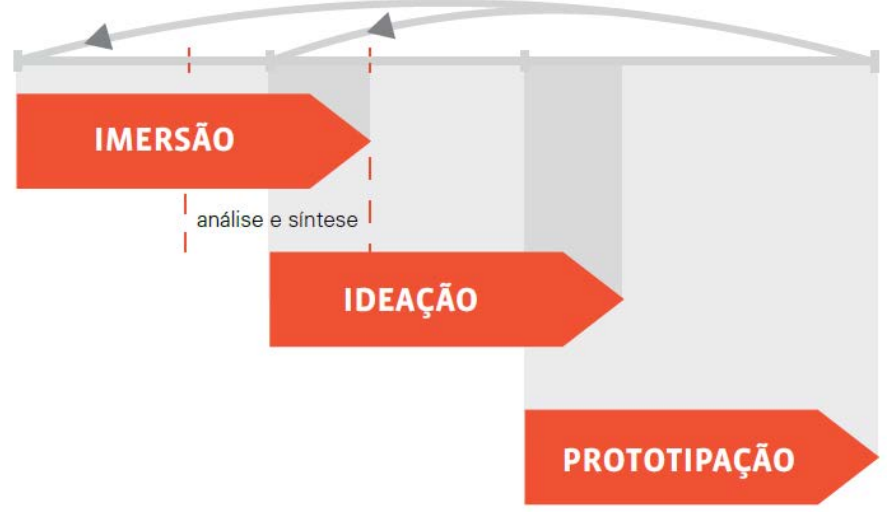


Ao que se refere a percepção de problemáticas, a disciplina conduziu os acadêmicos a realizarem pesquisas exploratórias como procedimento inicial fundamentada em discussões em sala, contato com profissionais, pesquisa desk e consultas em plataforma crowdsourcing (https://www.openideo.com/challenges). Tais procedimentos foram realizados de modo a ampliar as realidades percebidas pelos acadêmicos. Nesta etapa iniciaram reflexões acerca de demandas para atuação, de acordo com contextos sociais observados na região de Joinville, e a partir desta imersão preliminar, cada equipe elaborou uma indagação da temática que seria explorada. (Figura 3)

Figura 3 - Problematização e etapas processuais realizadas

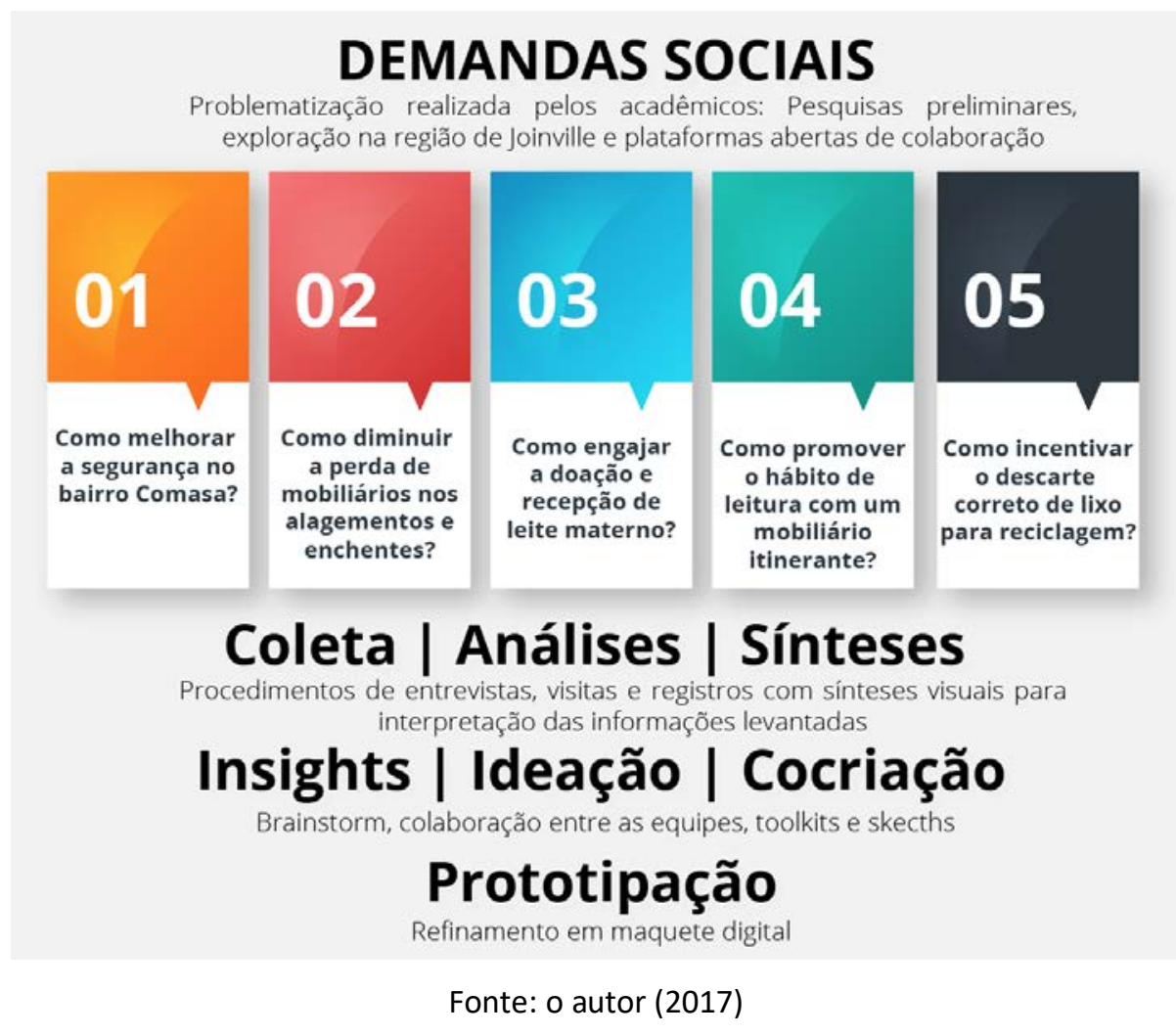

Conforme apresentado na figura 3, diversos questionamentos com relevância social surgiram, todos os aspectos discutidos em sala de aula apresentaram relevância ao tema proposto por cada equipe. Diante das problematizações realizadas pelos acadêmicos, relata-se os aspectos individuais abordados em cada proposta.

A segurança na cidade de Joinville vem sendo amplamente discutida, assaltos, acidentes, violência contra mulheres e idosos, entre outras ocorrências instigaram a problematização da equipe 01. Através das facilitações em sala e de uma delimitação geográfica da qual era uma vivência particular da equipe, foi gerada a problematização "Como melhorar a segurança no bairro Comasa?". A cidade de Joinville também apresenta uma vulnerabilidade social nos 
recorrentes episódios de alagamentos e enchentes, afetando um alto número de pessoas. Neste contexto social, a equipe 02 focou em trabalhar em "como diminuir a perda de mobiliários nos alagamentos e enchentes?" Já a equipe 03, pautou a proposta na vulnerabilidade de recémnascidos na alimentação exclusiva de leite materno. Como muitas mulheres por vezes são impossibilitadas de amamentar, é preciso ampliar o acesso a bancos de leite materno e engajar as doações, neste sentido a equipe abordou "como engajar a doação e recepção de banco de leite para recém-nascidos?". A equipe 04, percebeu em suas investigações a deficiência de serviços de atendimentos e espera em unidades de saúde pública da região, no sentido de explorar ainda mais a humanização destes espaços e verificando a falta do hábito de leitura e educação na localização dessas unidades, a problematização compreendeu em "como promover o hábito de leitura com um mobiliário itinerante?" A equipe 05 , verificou o impacto que o lixo gera e como a falta de seleção correta dos descartes causam desperdícios de materiais reutilizáveis, com isto, perceberam que dentro da instituição de ensino o hábito de separação de lixo era deficiente, propondo trabalhar em "Como incentivar o descarte correto de lixo para a reciclagem?"

Após realizada a problematização, foi iniciada a fase de imersão, na qual os acadêmicos planejaram as técnicas de coletas de dados, como: questionários, observações in loco, pesquisa desk e registros fotográficos. Esta etapa apresentou uma extensa pesquisa que foi elaborada ao longo dos encontros das aulas, compreendendo o universo teórico do problema, analisando o impacto das vulnerabilidades na vida das pessoas envolvidas, para então, realizar análises da coleta de informações levantadas. Os acadêmicos tabularam os dados, gerando sínteses visuais para discussão e aplicação de ferramentas de criatividade para a fase de ideação.

Figura 4 - Registros de análises colaborativas
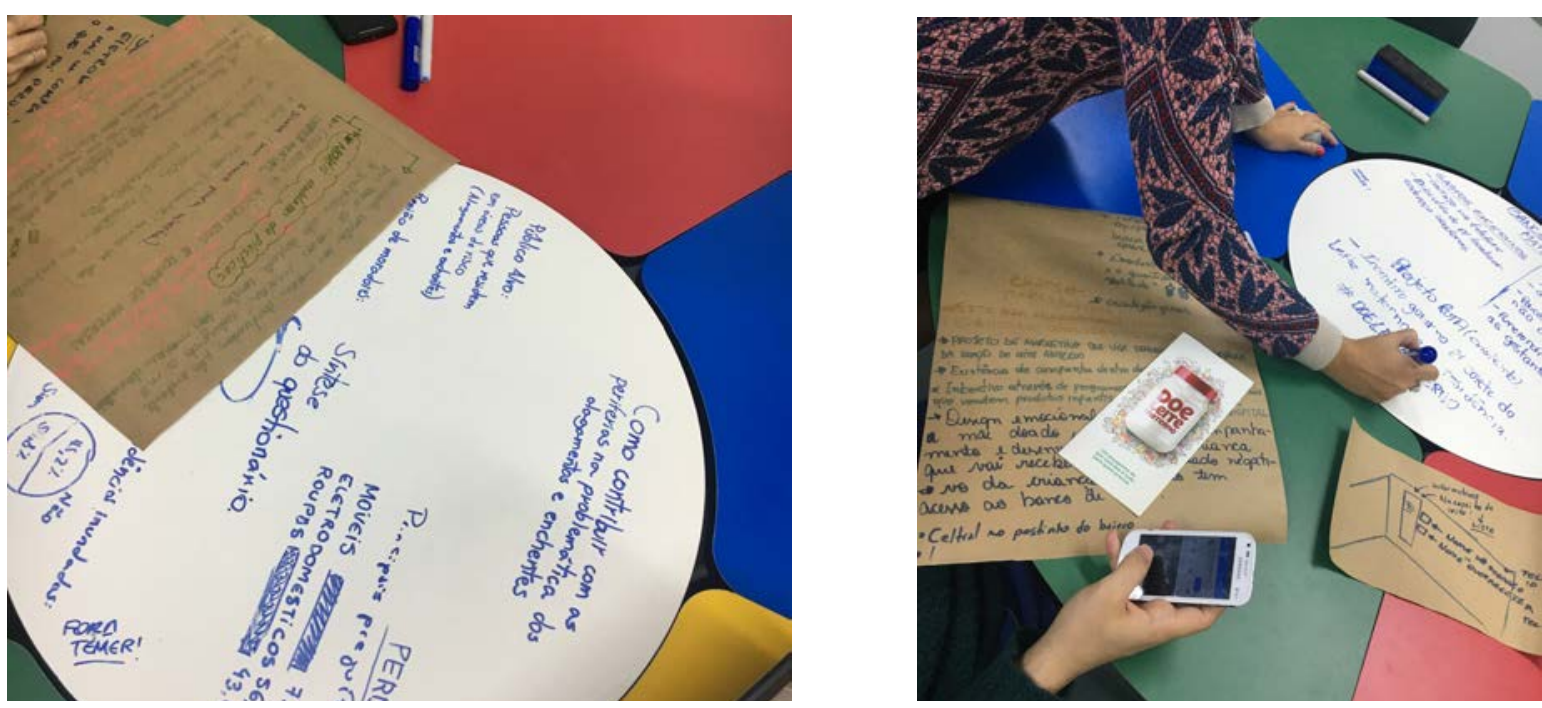

Fonte: o autor (2017)

A partir das análises realizadas, foi iniciada a fase da ideação, relacionada às gerações de ideias direcionadas ao tema do projeto. Foram utilizadas ferramentas de cocriação de modo a auxiliar a prática da criatividade na geração de alternativas de soluções. As equipes aplicaram técnica de Creative Toolkits com peças de lego, para gerar possibilidades e alternativas para realização de um posterior refinamento da ideia selecionada. 
Figura 5 - Registro da fase de ideação

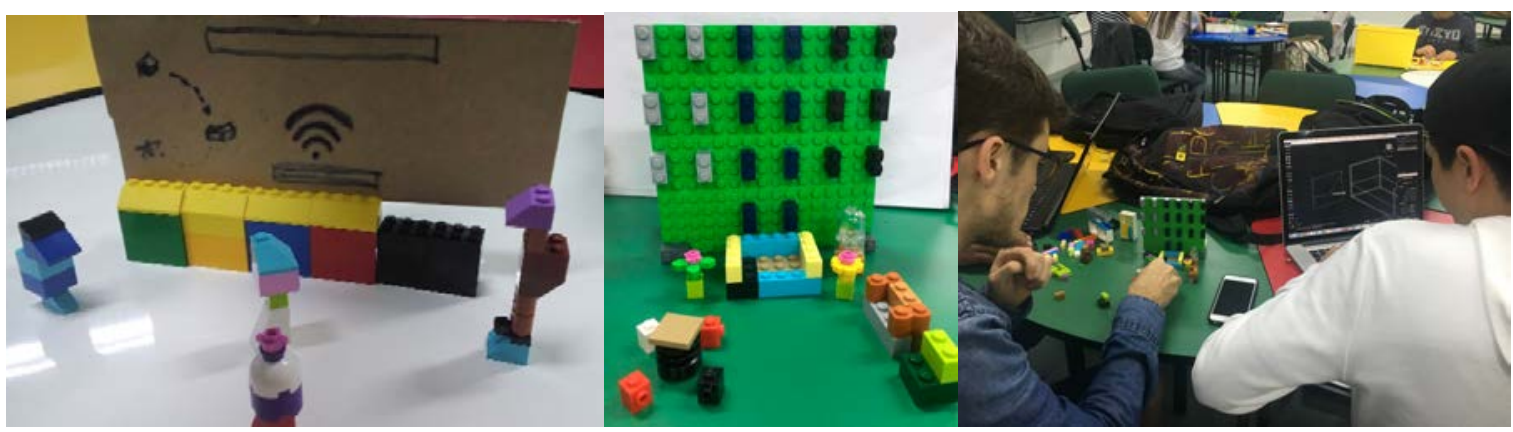

Fonte: o autor (2017)

A etapa de prototipação permitiu o refinamento das ideias adquiridas nas fases anteriores, as equipes aplicaram duas técnicas de realização de protótipos: Render digital e mockup físico.

A proposta da equipe 01 considerou um amplo público alvo para desenvolver uma solução que atendesse ao problema da falta de segurança, tanto da população moradora, como da que frequenta o bairro, comerciantes, visitantes e também dos policiais. A solução contemplou um drone, que possui a função de monitorar o espaço aéreo e limitação geográfica de pontos críticos do bairro. Através de uma câmera, envia vídeos e imagens simultâneas para a base policial, foto scanners para reconhecimento facial e sirenes para a população em momentos de alerta ou risco.

Figura 6 - Resultado equipe 01

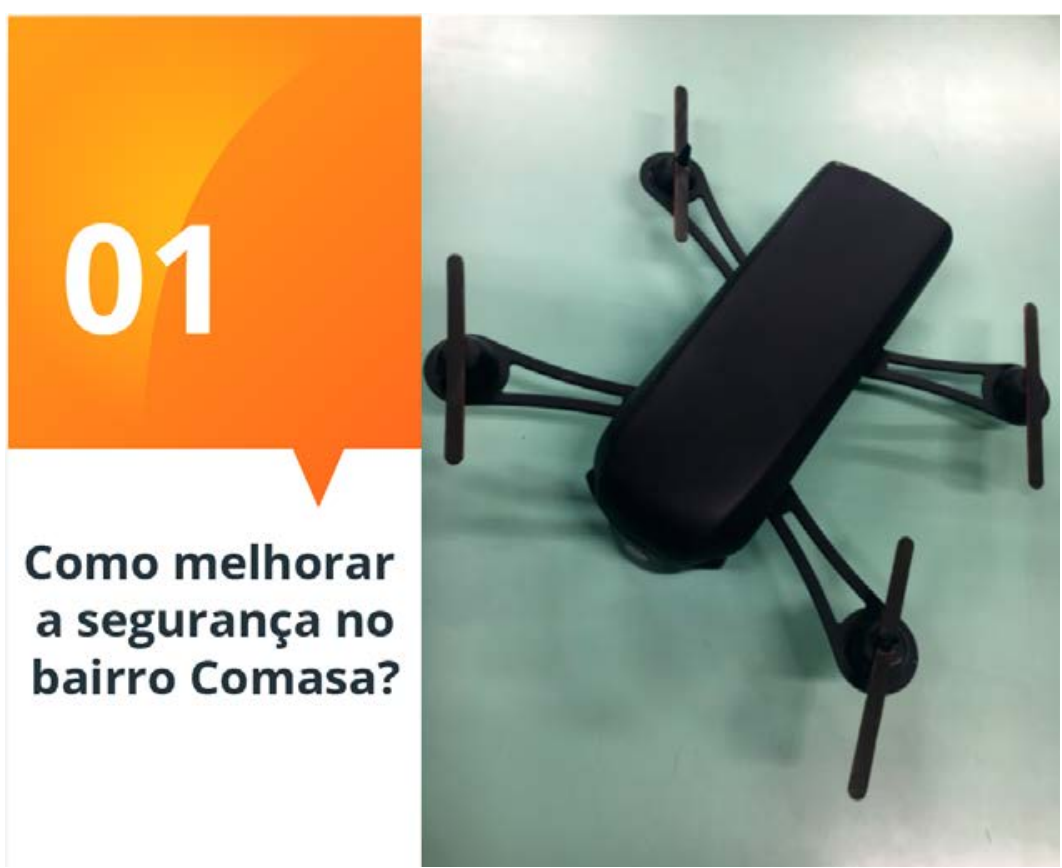

Fonte: o autor (2017) 
Com as informações levantadas pela equipe 02 , detectou-se que a perda de alguns mobiliários são recorrentes nas enchentes e alagamentos e obteve-se a percepção da ação imediata dos moradores de áreas de risco em empilhar apressadamente seus pertences em tijolos e materiais encontrados na rua. Esses elementos foram norteadores para repensar soluções imediatas e de baixo custo. Com este insight, a equipe atuou em dispositivos de empilhamentos de mobiliários que pudessem ser fixados nas paredes e partes traseiras das peças, evitando danificar o mobiliário que mais eram perdidos nos alagamentos ou enchentes.

Figura 7 - Resultado equipe 02

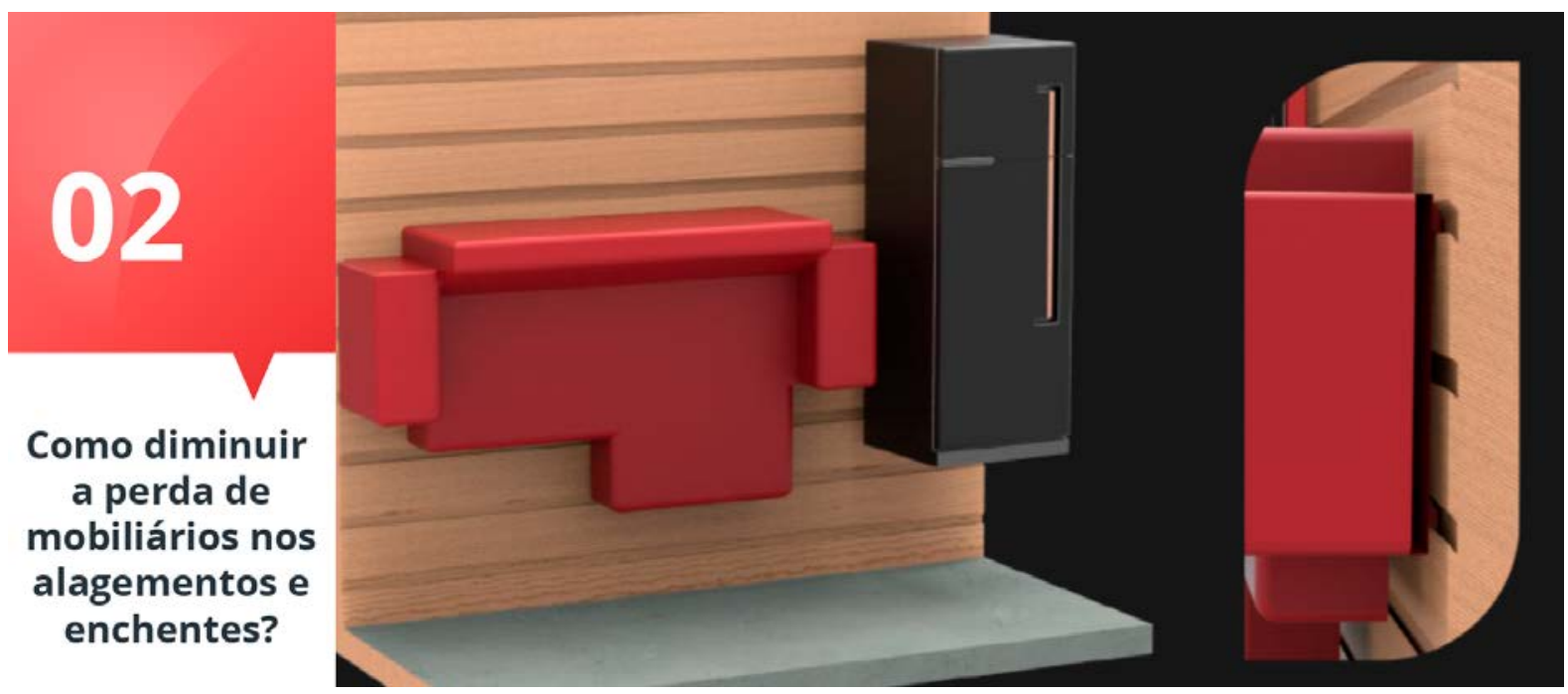

Fonte: o autor (2017)

Na proposta da equipe 03, foi detectado que, mais que a falta de engajamento para a doação de leite, as possíveis doadoras não possuem acesso às informações de procedimentos para doar bem como dos locais de coleta do leite. Diante disto, a solução apresentada foi um aplicativo com funções de esclarecimentos acerca da higienização e procedimento de coleta e mapa com GPS (Global Positioning System) dos locais de coleta. No que refere-se ao engajamento, atribuíram um serviço em parceria com restaurantes, retribuindo assim as doações em forma de descontos em determinados estabelecimentos comerciais que seriam apoiadores da causa. 
Figura 8 - Resultado equipe 03

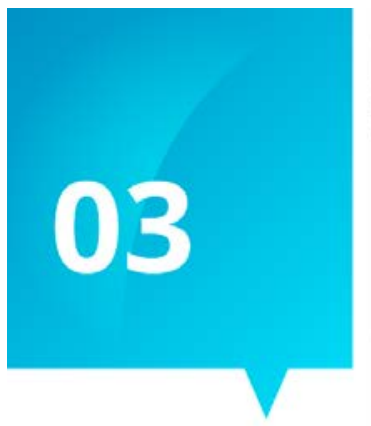

Como engajar a doação e recepção de leite materno?
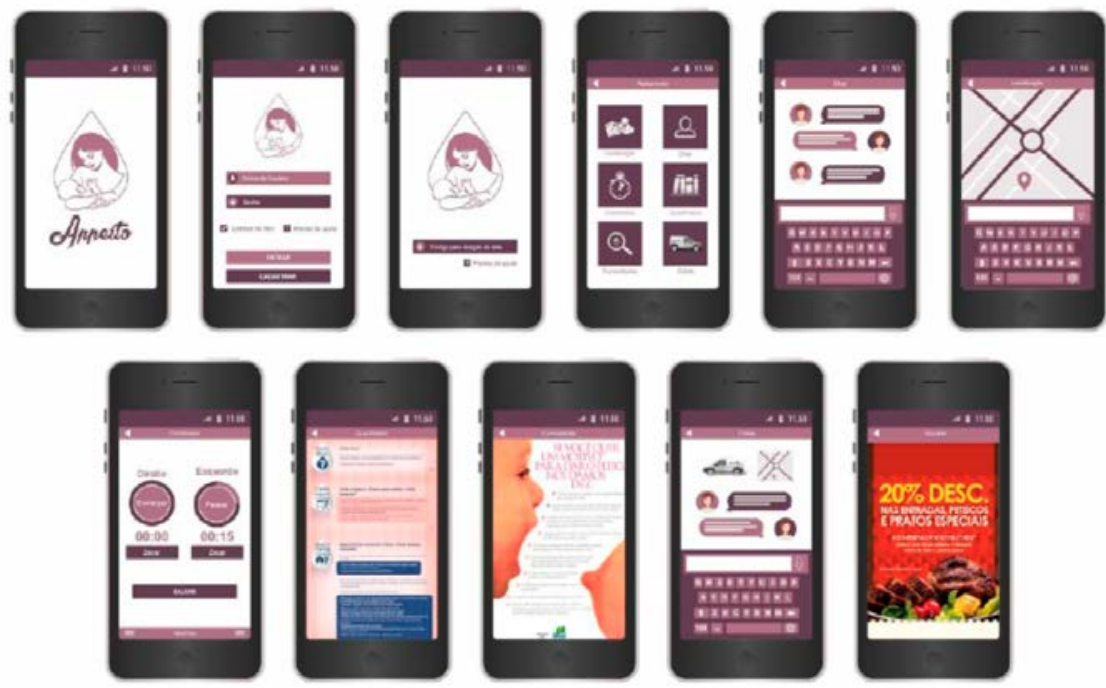

Fonte: o autor (2017)

Na proposta da equipe 04, além de refletir na humanização dos espaços de atendimento e espera de unidades de saúde pública, a equipe considerou o aspecto da falta de acesso da população à livros. Neste sentido, propuseram uma estante itinerante de livros como estímulo a estudo e educação, impactando o ambiente de maneira sútil, com facilidade de transporte e de baixo custo.

Figura 9 - Resultado equipe 04

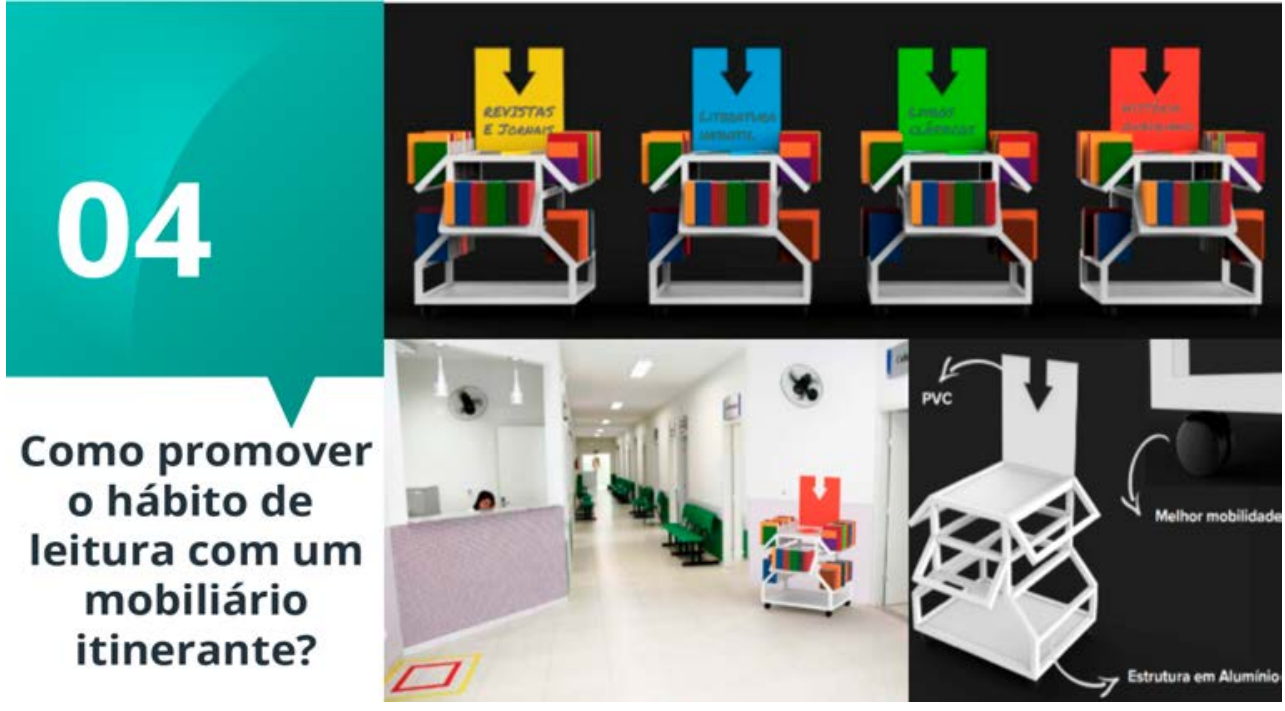

Fonte: o autor (2017) 
A equipe 05, ao considerar os insights das informações levantadas na etapa de imersão, projetaram um mobiliário urbano utilizando a interação e gamificação como elementos principais da solução. A lixeira interativa desenvolvida foi a Smart trash, inspirada em dispositivos mobile amplamente utilizados pelos usuários, planejada em promover interatividade e oferecer recompensas, como sinal de internet via wi-fi gratuito, após o descarte correto do lixo. A gamificação surge como conceito por meio de uma proposta de impacto ambiental que buscou alternativas para estimular a incorporação de hábitos de reciclagem e separação de lixo no cotidiano das pessoas.

Figura 10: Resultado equipe 05

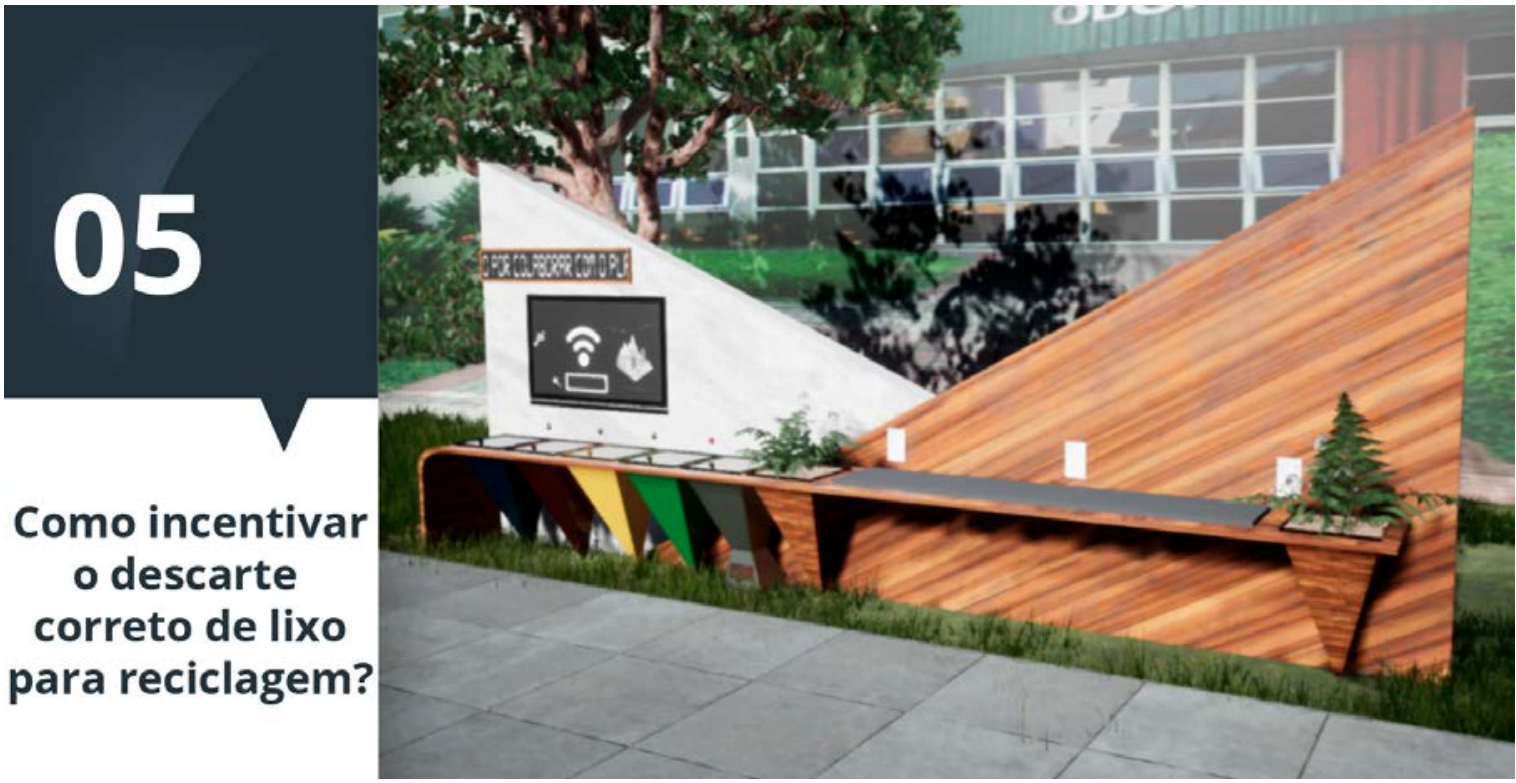

Fonte: o autor (2017)

Na década de 70 Papanek (1977), já questionava a profissão do designer sobre o impacto ambiental e social do seu trabalho, realçando a importância de perceber e solucionar os problemas reais da sociedade. Argumentava que numa era de produção em massa, o design havia se tornado um instrumento poderoso na configuração de ferramentas e ambientes para o homem e destacava a importância de se compreender as necessidades básicas dos seres humanos e sua relação com o design. Lima e Martins (2011 apud BRAGA, 2011, p. 115). Diante das propostas apresentadas pelos acadêmicos, percebe-se a existência da preocupação minuciosa em atribuir relevância para as pessoas por meio dos projetos em cada solução gerada. Mesmo que as propostas sejam conceituais ou não viáveis para implementação, observa-se o desenvolvimento criativo para propor soluções em demandas tão pouco exploradas no contexto social da região de Joinville.

\section{Considerações Finais}

Diante da abordagem de ensino aplicada no primeiro ano (2014) com os resultados pedagógicos alcançados na vivência no quarto ano de graduação (2017), percebe-se a evolução do 
conhecimento adquirido pelos estudantes acerca das técnicas, ferramentas e processos do design thinking. Aponta-se aspectos que influenciaram diretamente esta segunda vivência, sendo: (1) o uso de salas de aula projetadas para metodologias ativas de ensino-aprendizagem; (2) a temática de impacto social do desafio trabalhado; (3) o aprimoramento técnico dos acadêmicos.

Conforme relatado, o processo de ensino-aprendizagem contemplando metodologia ativa e por meio do design thinking, compreendeu o desenvolvimento de habilidades e competências dos estudantes desde a etapa de problematização até os resultados projetuais da prototipação. Destaca-se algumas competências e habilidades que são intrínsecas às características da abordagem do design thinking, como: empatia, colaboração, cocriação e processo centrado no usuário, fatores esses que também contribuíram para oportunizar o direcionamento de soluções diferenciadas no contexto de demandas sociais.

O processo de ensino-aprendizagem explorado subsidiou o desenvolvimento da ciência com a prática, unindo do contexto social da condução de pesquisas teóricas e a campo. Ao observar os objetivos que a ONU propõe junto ao MEC acerca de inovação pedagógica no ensino superior, entende-se a premissa de formar de cidadãos e profissionais que sejam comprometidos com desenvolvimento social. Neste sentido, aponta-se a articulação desenvolvida contemplando a exploração de algumas das 169 metas que atendem as propostas em atividades desenvolvidas, visando a melhoria de condições ambientais, sociais e existenciais (ONU, 2015).

A contribuição do presente artigo compreende na disseminação de conteúdo acerca das abordagens contemporâneas da sala de aula para propostas de metodologias ativas. Promovendo ainda, a publicação e valorização de estudos projetuais de estudantes recém formados, reconhecendo a dedicação em projetos que necessitam de atenção da comunidade acadêmica para construir habilidades e competências dos novos profissionais cidadãos.

\section{Referências}

BRAGA, M. C. (Org.). O papel social do design gráfico. História, conceitos \& atuação profissional. São Paulo: Senac, 2011.

BROWN, T. Design thinking: uma metodologia poderosa para decretar o fim das velhas ideias. Rio de Janeiro: Elsevier, 2010.

CANÔNICA, Rosangela. ANGEOLETI, Larissa. SANTA ROSA, G. José. Facetas e Aplicações do Design Centrado no Usuário - Ergotrip Design. Rio de Janeiro: Rio Books, 201.

CAVALCANTI, Carolina Costa. FILATRO, Andrea. Design thinking na educação presencial, a distância e corporativa. São Paulo: Saraiva, 2016.

MALARD, Maria Lúcia. Forma, arquitetura. Belo Horizonte: Escola de Arquitetura. UFMG, 2003.

ONU, Nações Unidas do Brasil. Momento de ação global para as pessoas e para o planeta. Disponível em https://nacoesunidas.org/pos2015/. Acesso em 03/04/2018.

PAPANEK, Victor. Design para el mundo real: ecologia humana e cambio social. Madrid: Ediciones Blume, 1977.

VIANNA, M. et al. Design thinking: inovação em negócios. Rio de Janeiro: MJV, 2012. 